\title{
Phosphorylation of Neurofilament Proteins and Chromatolysis Following Transection of Rat Sciatic Nerve
}

\author{
Margi E. Goldstein, Harold S. Cooper, Jennifer Bruce, Martin J. Carden, Virginia M.-Y. Lee, and William W. \\ Schlaepfer \\ Division of Neuropathology, Department of Pathology and Laboratory Medicine, University of Pennsylvania Medical \\ School, Philadelphia, Pennsylvania 19104
}

\begin{abstract}
States of phosphorylation of neurofilament proteins were examined in the perikarya of rat sensory and motor neurons between 3 and $28 \mathrm{~d}$ following either a distal transection [6$7 \mathrm{~cm}$ from the L4-L5 dorsal root ganglia (DRG)] or a proximal transection (1-2 cm from the L4-L5 DRG) of the sciatic nerve. Paraffin sections of the right (experimental) and left (control) L4 and L5 DRG from animals with unilateral transection of the right distal sciatic nerve were stained immunocytochemically with monoclonal antibodies to phosphorylation-dependent (NF-P), dephosphorylation-dependent (NF-dP), or phosphorylation-independent (NF-ind) epitopes on the largest (NF200), mid-sized (NF150), or smallest (NF68) neurofilament protein subunits. Increased immunoreactivity to NF-P on NF200 and NF150 was detected in experimental DRG at $10 \mathrm{~d}$, peaking by $20 \mathrm{~d}$, and declining to near control levels by $28 \mathrm{~d}$. Conversely, immunoreactivity to NF-dP declined in experimental DRG beginning at $6 \mathrm{~d}$, reaching a maximum decline at 10-16 d, and returning to near control levels by $28 \mathrm{~d}$. Immunocytochemical changes were confirmed with biochemical studies on tissue homogenates that demonstrated an increase of immunoreactivity to NF-P and a decrease of reactivity to NF-dP in the experimental DRG. Changes in immunoreactivities to NF-P and NF-dP were observed only in the perikarya of large neurons and were closely associated with chromatolytic changes in these neurons. Marked enhancement of chromatolysis, as well as the immunoreactivities to NF-P and NF-dP, occurred following a proximal (left side) versus distal (right side) transection in the same animal. Motor neurons of transected nerves showed only minimal changes of chromatolysis or in immunoreactivities to NF-P and NF-dP. These studies indicate that the phosphorylation state of neurofilaments is altered in response to axotomy and that these changes are associated with chromatolysis.
\end{abstract}

Chromatolysis is a reactive change of neuronal perikarya to axonal injury. The classical histological features, namely, the

\footnotetext{
Received Aug. 22, 1986; revised Dec. 5, 1986; accepted Dec. 15, 1986.

This study was supported by Grants NS- 15572 and NS-18616 from the NIH, by Grant CA-09140-12 from the National Cancer Institute, by a fellowship (to M.J.C.) from the Amyotrophic Lateral Sclerosis Association of America, and by a grant from Sandoz, Inc.

Correspondence should be addressed to Dr. Margi E. Goldstein, Laboratory of Neuropathology, Department of Pathology and Laboratory Medicine, 435 Johnson Pavition, University of Pennsylvania Medical School, 36th and Hamilton Walk, Philadelphia, PA 19104-6079.

Copyright (C) 1987 Society for Neuroscience $0270-6474 / 87 / 051586-09 \$ 02.00 / 0$
}

peripheral margination of Nissl substance, nuclear displacement, and nucleolar enlargement (Guth, 1956; Kirkpatrick, 1968; Lieberman, 1971; Grafstein, 1975; Torvik, 1976; Hughs, 1978; Tennyson and Gershon, 1984) are manifestations of the cell's attempt to regenerate the injured axon (Cragg, 1970; Price and Porter, 1972; Grafstein, 1975; Torvik, 1976; Hall et al., 1978). The dependence of these changes on the type and location of the lesion (Ilumbertson, 1963; Watson, 1968; Lieberman, 1971; Torvik and Skjorten, 1971; Torvik, 1976; Aldskogius and Arvidsson, 1978; Hall et al., 1978; Hughs, 1978; Sterman and Delannoy, 1985) indicates that the chromatolytic reaction is mediated by retrograde signals from the site of injury (Cavanaugh, 1951; Carmel and Stein, 1969; Cragg, 1970; Torvik, 1976). The nature of the retrograde signals and the manner by which these signals mediate changes in neuronal metabolism (reviewed by Lieberman, 1971) are poorly understood.

Alterations of the neuronal cytoskeleton comprise a major component of the chromatolytic reaction. Tubulin and actin are the major cytoskeletal components of growth cones and regenerating nerves (Peters and Vaughn, 1967; Fine and Bray, 1971; Yamada et al., 1971; Marchisio et al., 1978) and undergo a marked enhancement in synthesis (Heacock and Agranoff, 1976; Burrell et al., 1979; Giulian et al., 1980; Sinicropi and Mcllwain, 1983) and axonal transport (Lasek and Hoffman, 1976; Giulian et al., 1980; Hoffman and Lasek, 1980; Skene and Willard, 1981) following nerve transection. By contrast, neurofilaments have a very limited presence, if any, in growth cones (Peters and Vaughn, 1967; Shaw et al., 1981). Both the synthesis (P. N. Hoffman, personal communication) and the axonal transport of neurofilament proteins are decreased after axotomy, resulting in a diminished number of neurofilaments and reduced axonal caliber in axonal segments proximal to a nerve transection (Hoffman and Lasek, 1980). Paradoxically, an increase of neurofilaments (Pannese, 1963; Lieberman, 1971; Torvik and Skjorten, 1971; Zelena, 1971; Horoupian and Wisniewski, 1972; Price and Porter, 1972; Wisotzkey and Cole, 1974; Torvik, 1976; Sinicropi and McIlwain, 1983) and an enhanced immunohistochemical staining for neurofilaments (Moss and Lewkowicz, 1983; Drager and Hofbauer, 1984) have been reported in the perikarya of transected nerves.

The accumulation of neurofilaments in perikarya and their depletion from proximal axons of transected nerves indicate a block in the movement of neurofilaments from the perikarya into the axon. Diminished perikaryal transport of neurofilaments could be due to an intrinsic alteration of neurofilaments, such as an increase in their state of phosphorylation. Alterna- 
$\%$ CHROMATOLYSIS : LARGE CELLS, DRG

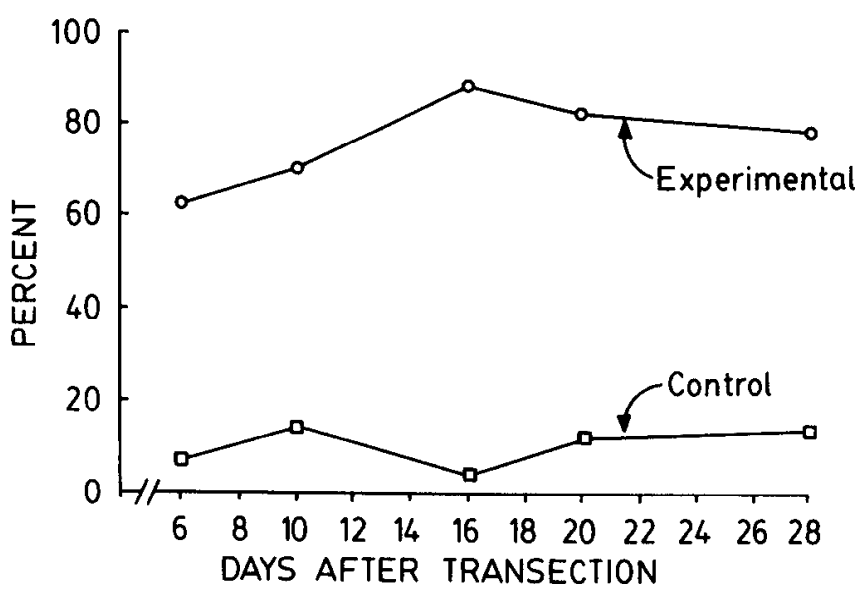

Figure 1. Percentage of chromatolysis in the large cell population of the L4 and L5 dorsal root ganglia (DRG) as a function of the number of days following transection of the sciatic nerve. Squares, Left (control) side. Circles, Right (experimental) side. Chromatolysis of large cells in the control DRG remained at a mean level of $10.2 \%$ throughout the course of the study. In the experimental DRG, however, $61.8 \%$ of the large cells were chromatolytic at $6 \mathrm{~d}$, increasing to $87.9 \%$ at $16 \mathrm{~d}$, and decreasing to $78.9 \%$ at $28 \mathrm{~d}$.

tively, the increased immunoreactivity to neurofilaments, even to phosphorylated forms (Moss and Lewkowicz, 1983; Drager and Hofbauer, 1984), could reflect an extrinsic block, leading to an accumulation of neurofilaments that are normally transported into the axon. The present study has addressed these questions with biochemical and immunochemical techniques, using a panel of well-characterized antibody probes to analyze phosphorylated and dephosphorylated forms of neurofilament proteins in the perikarya of transected neurons.

\section{Materials and Methods}

Nerve transection. The right sciatic nerve of 38 Sprague-Dawley rats (300 gm) was transected $6-7 \mathrm{~cm}$ from the L4-L5 dorsal root ganglia (DRG), $2 \mathrm{~cm}$ below the level of the sciatic notch. Each animal was anesthetized with ether, and a $1 \mathrm{~cm}$ segment of nerve was excised with scissors, applying minimal traction on the proximal portion of the nerve. The skin incision was closed with metal clips. Animals were killed between 6 and $28 \mathrm{~d}$. Additionally, in 10 of the rats, the left sciatic nerve was transected 1-2 cm from the L4-L5 DRG; the rats were allowed to survive for $3,6,12,18$, and $25 \mathrm{~d}$.

Immunocytochemistry. Immunocytochemical studies were conducted on tissues that were fixed by perfusion through the ascending aorta. At $6,10,16,20$, and $28 \mathrm{~d}$ after transection, pairs of rats were perfused with approximately $200 \mathrm{ml}$ of ice-cold PBS-EGT $\Lambda$ ( $2 \mathrm{~mm})$, then with $400 \mathrm{ml}$ of cold Bouin's fixative. The right (experimental) and left (control) L4 and L5 DRG and lumbar spinal cords were dissected, excised, and immersed overnight in Bouin's fixative $\left(4^{\circ} \mathrm{C}\right)$. Control and experimental DRG from each animal were processed identically, undergoing extensive washing in PBS, dehydration through a series of alcohols, and embedding in paraffin. Six micron sections were cut and mounted on chrom-alum-subbed slides, deparaffinized in xylene, and rehydrated through a series of alcohols. Endogenous peroxidase activity was removed by incubation in hydrogen peroxide and methanol.

Nonspecific binding sites were blocked with $3 \%$ BSA for 30 min prior to heing incubated with primary antibody overnight. Primary incubations were conducted with serial dilutions of hybridoma supernatants (described below), which were diluted with 3\% BSA and applied overnight at room temperature. Control incubations were conducted with $3 \%$ BSA in the absence of antibody. After removal of the primary antibodies the tissue sections were incubated with biotinylated mouse or rat antibody diluted with $3 \%$ BSA (1:750 and 1:500, respectively) for $30 \mathrm{~min}$, then with avidin-biotin complex (Vector Labs, Burlingame,
CA) for $30 \mathrm{~min}$. Each incubation was followed by extensive washing with Tris-buffered saline (TBS). Staining was developed with diaminobenzidine (DAB) at $0.5 \mathrm{mg} / \mathrm{ml}$ in $0.1 \mathrm{M}$ Tris- $\mathrm{HCl}, \mathrm{pH} 7.6$, with 0.01 $\mathrm{M}$ imidazole and $0.03 \%$ hydrogen peroxide. The sections were lightly counterstained with hematoxylin.

Biochemistry. Biochemical studies were conducted on tissues perfused with $500 \mathrm{ml}$ of ice-cold PBS-EGTA 1,2, and 3 weeks after transection, using 6 rats at each survival time point. Right (experimental) and left (control) L4 and L5 DRG were pooled and homogenized at a 1:20 wt/ vol ratio in $0.1 \mathrm{~m}$ Tris, pH 6.8, $8 \mathrm{~m}$ urea, 2\% SDS, 5\% 2-mercaptoethanol, and $0.05 \%$ bromophenol blue, centrifuged for $15 \mathrm{~min}$ at $15,600 \times \mathrm{g}$ in an Eppendorf microcentrifuge, and the supernatants aliquoted and frozen at $-20^{\circ} \mathrm{C}$. Protein concentration in each sample was determined by applying the samples to filter paper and staining them with Coomassie G-250, essentially as described by McKnight (1977). BSA was used as a standard.

Proteins were visualized on immunoblots that were stained immunocytochemically using the peroxidase-antiperoxidase (PAP) method (L. A. Sternberger et al., 1970; Sternberger, 1986). Equal amounts of control and experimental DRG homogenates were separated overnight on $7.5 \%$ polyacrylamide gels (Laemmli, 1970) at $40 \mathrm{~V}$ constant voltage, transferred to nitrocellulose paper $(0.45 \mu \mathrm{m}$; Schleicher and Schuell) with $0.025 \mathrm{~m}$ Tris- $\mathrm{HCl}, \mathrm{pH} 8.3,0.05 \mathrm{M} \mathrm{NaCl}, 0.19 \mathrm{M}$ glycine, and $10 \%$ methanol (Towbin et al., 1979), and stained with the primary antibodies described below as undiluted hybridoma supernatants. Immunoblots were incubated with $1 \%$ powdered milk in TBS for $30 \mathrm{~min}$ to block nonspecific binding sites, with primary antibodies for $3 \mathrm{hr}$, with goat anti-mouse antiserum (Cappel) diluted $1: 100$ with $1 \%$ powdered milk in TBS for 30 min, with monoclonal PAP diluted 1:200 with $1 \%$ powdered milk in TBS, and developed with $0.5 \mathrm{mg} / \mathrm{ml} \mathrm{DAB}$, with $0.01 \mathrm{M}$ imidazole and $10 \mu \mathrm{l}$ of $30 \%$ hydrogen peroxide. Each incubation was followed by extensive washing with TBS.

Antibody reactivity was quantitated using the ELISA assay (Kennett, 1980). Dilutions of control and experimental DRG homogenates were made with $0.5 \%$ Triton X-100 and 3\% normal horse serum (NHS) in TBS. The wells of 96-well plates (Linbro) were coated overnight at $4^{\circ} \mathrm{C}$ with a 1:80 dilution of DRG homogenate; this dilution yields maximum reactivity of antibody while overcoming the inhibitory effects of SDS and urea in the homogenization buffer. Triton X-100 was included in the diluent to diminish the inhibitory effect of SDS and urea on antibody reactivity. The wells were blocked with $3 \%$ NHS in TBS for 30 min at room temperature, washed, then incubated with undiluted hybridoma supcrnatants for $2 \mathrm{hr}$ at room tcmperature, washed, and finally incubated with HRP-conjugated sheep anti-mouse or sheep anti-rat antibody (Cappel) diluted 1:1000 with 3\% NHS in TBS for $2 \mathrm{hr}$ at room temperature and washed again. The wells were developed by incubation with a mixture of $10 \mathrm{mg} O$-phenylenediamine dihydrochloride (OPD), $10 \mathrm{ml}$ of $0.1 \mathrm{M}$ citrate buffer, $\mathrm{pH} 4.5$, and $4 \mu \mathrm{l}$ of $30 \%$ hydrogen peroxide. The plates were read in a multiscan spectrophotometer at a wavelength of $450 \mathrm{~nm}$.

Antibodies. Immunocytochemical and biochemical studies were conducted using a well-characterized panel of monoclonal antibodies raised against bovine neurofilaments (Lee et al., 1982, 1984) and rat neurofilaments (V. M.-Y. Lee, unpublished observations) with retained immunoreactivity in Bouin's fixed tissues (Trojanowski et al., 1985). Antibodies RMO 24.9, RMO 217, and Ta51 recognized different phosphorylation-dependent epitopes on NГ200 (NF200-P); RMO 108.1, RMO 45, and RMO 55 recognized different phosphorylation-dependent epitopes on NF150 (NF150-P); RMDO 20.11 recognized a dephosphorylation-dependent epitope on NF200 (NF200-dP); and RMO 194, RMDO 10, and RMS 21 recognized phosphate-independent epitopes on NF200 (NF200-ind), NF150 (NF150-ind), and NF68 (NF68-ind), respectively.

Quantitation. Antibody reactivity in sections of control and experimental DRG was quantitated by counting 100-200 neuronal perikarya per DRG on coded slides with the aid of an ocular grid. Cell bodies were scored by size, the presence or absence of chromatolysis, and the presence or absence of immunocytochemical staining. Chromatolysis was defined by the peripheral displacement of Nissl substance. Immunoreactive cells were identified as those with perikaryal staining that was clearly above background. The results were expressed as the percentage of large cells that were chromatolytic (no. of large chromatolytic cells/total no. of large cells), the percentage of large cells that were chromatolytic and stained (no. of large, chromatolytic, and stained cells/ total no. of large cells), or as the percentage of large cells that were 


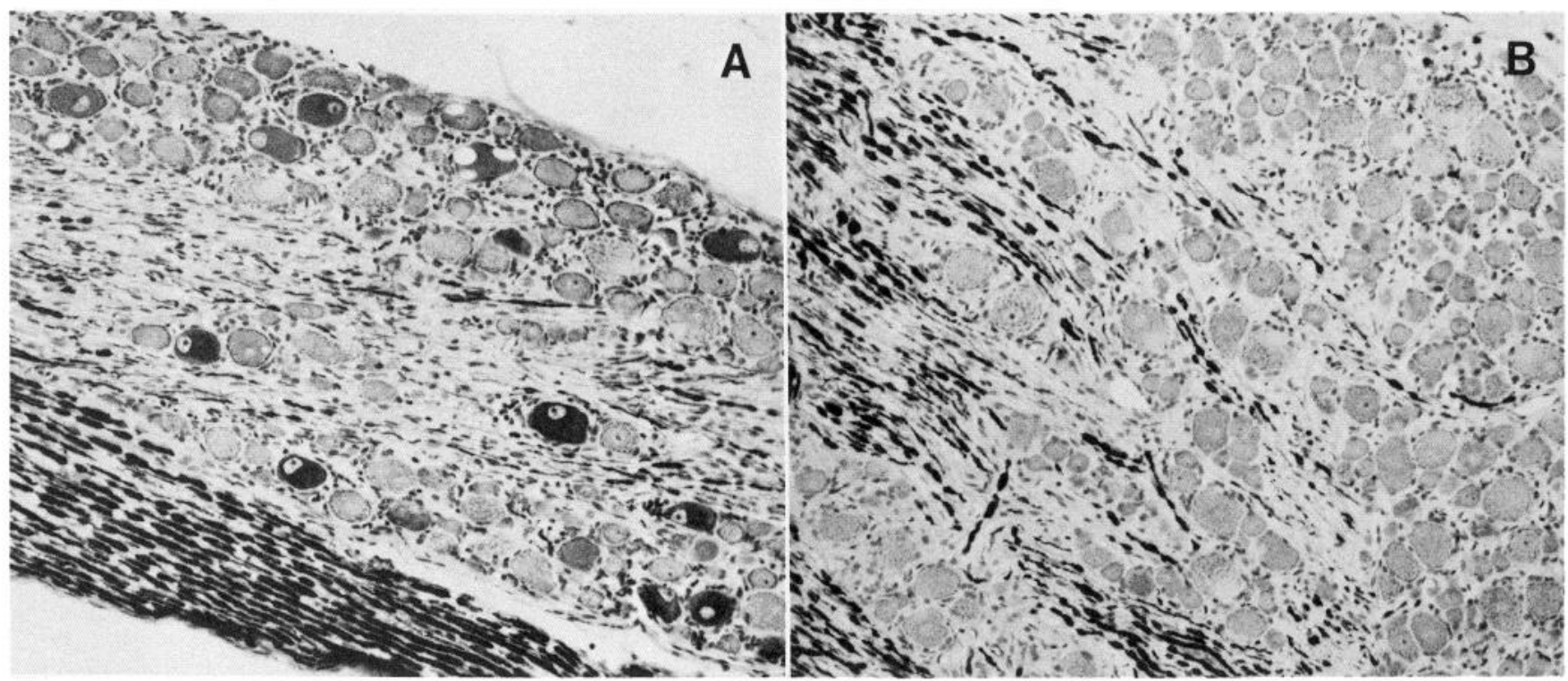

Figure 2. Photomicrograph of a $6 \mu \mathrm{m}$ paraffin section of the $(A)$ right (experimental) dorsal root ganglion and $(B)$ left (control) dorsal root ganglion $16 \mathrm{~d}$ following transection of the right sciatic nerve. Sections were stained immunocytochemically with the phosphorylation-dependent monoclonal antibody RMO 24.9 at a dilution of 1:10. In the experimental DRG, peripheral margination of the Nissl substance, indicative of chromatolysis, is seen in many of the small and large perikarya. The large, chromatolytic cells are preferentially stained by RMO 24.9 . In the control DRG, few cells are chromatolytic, and at this antibody dilution a few cells in the large and small populations are faintly stained.

nonchromatolytic and stained (no. of large, nonchromatolytic, and stained cells/total no. of large cells) for antibody RMO 24.9 to NF-P; they were also expressed as the percentage of large cells that were chromatolytic and unstained (no. of large, chromatolytic, and unstained cells/total no. of large cells) or the percentage of large cells nonchromatolytic and unstained (no. of large, nonchromatolytic, and unstained cells/total no. of large cells) for antibody RMDO 20.11 to NF-dP.

The ELISA data were expressed as the ratios of the absorbance readings for the experimental and control DRG. The experimental values obtained from reactivity with the phosphorylation- or dephosphorylation-dependent antibodies were normalized on the basis of the values obtained from reactivity with a phosphate-independent antibody. Wilcoxon's Rank-Sum test was used to determine whether the experimental values were significantly different from the control values.

\section{Results}

Histology

Neuronal populations were readily classified according to their size. The large neuronal cell population of experimental and control DRG represented an average of $35 \%$ of the total cell population, in agreement with the large class A cell population defined by Lawson et al. (1974), Lawson (1979), and Sommer et al. (1985). Of the large cell population in control DRG, chromatolysis, as defined in our study (see Materials and Methods), was observed at a mean level of $10.2 \%$ at all survival times. In the experimental DRG, however, $61.8 \%$ of the large cells were chromatolytic at $6 \mathrm{~d}$ after transection. Chromatolysis among large cells peaked at $16 \mathrm{~d}$ posttransection at a value of $87.9 \%$ and declined slightly to a value of $78.9 \%$ at $28 \mathrm{~d}$ (Fig. 1).

\section{Immunocytochemistry of normal DRG}

Neurofilament immunoreactivity was observed in the axons and neuronal perikarya of the DRG. Perikaryal staining occurred preferentially in the large cell population, as noted by Anderton et al. (1982), Sharp et al. (1982), Lawson et al. (1984), and Price (1985). The extent of immunoreactivity in neuronal perikarya,

\section{$\%$ LARGE CELLS STAINED, DRG NF 200-P (RMO 24.9, 1:10)}

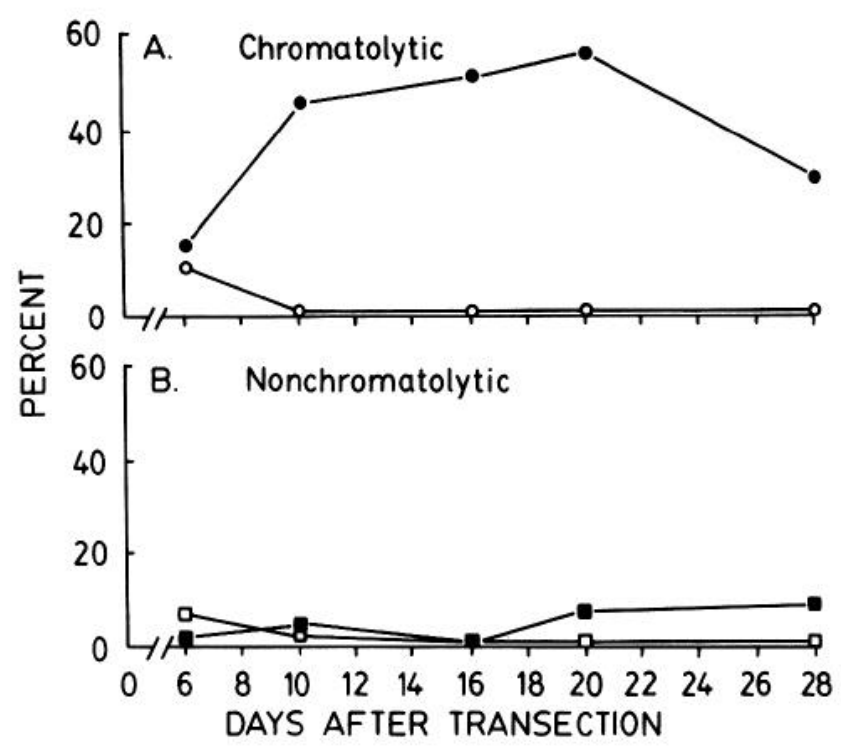

Figure 3. Percentage of large DRG cells stained in paraffin sections by the phosphorylation-dependent antibody RMO 24.9 at a dilution of $1: 10$ as a function of the number of days following transection of the right sciatic nerve. Circles, chromatolytic cells; squares, nonchromatolytic cells; closed symbols, cells from the right (experimental) DRG; open symbols, cells from the left (control) DRG. The percentage of cells stained in the large, chromatolytic cell population of the experimental DRG increases over the control following transection $(A)$, indicating an increase in phosphorylation, while the percentage of cells stained in the large, nonchromatolytic cell population of the experimental DRG remains at control levels $(B)$. An increase in phosphorylation in the large cell population may therefore be correlated with an increase in chromatolysis. 


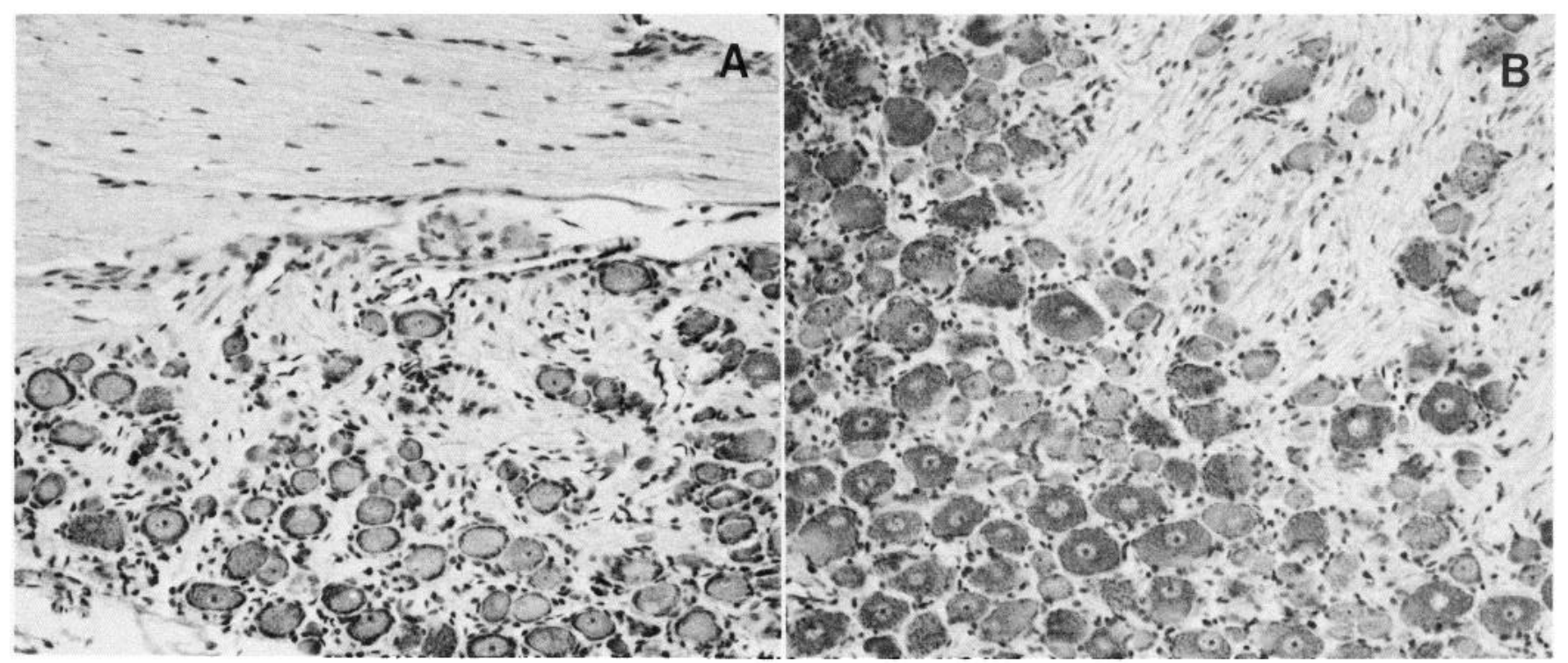

Figure 4. Photomicrograph of a $6 \mu \mathrm{m}$ paraffin section of the $(A)$ right (experimental) dorsal root ganglion and $(B)$ left (control) dorsal root ganglion $16 \mathrm{~d}$ following transection of the right sciatic nerve. Sections were stained immunocytochemically with the dephosphorylation-dependent monoclonal antibody RMDO 20.11 at a dilution of 1:100,000. In the experimental DRG, peripheral margination of the Nissl substance is seen in many of the small and large perikarya. Few cells are stained immunocytochemically at this dilution. In the control DRG, few cells appear chromatolytic, while many, preferentially large, cells are stained immunocytochemically.

$\%$ LARGE CELLS UNSTAINED, DRG NF 200-dP (RMDO 20.11, 1:100,000)

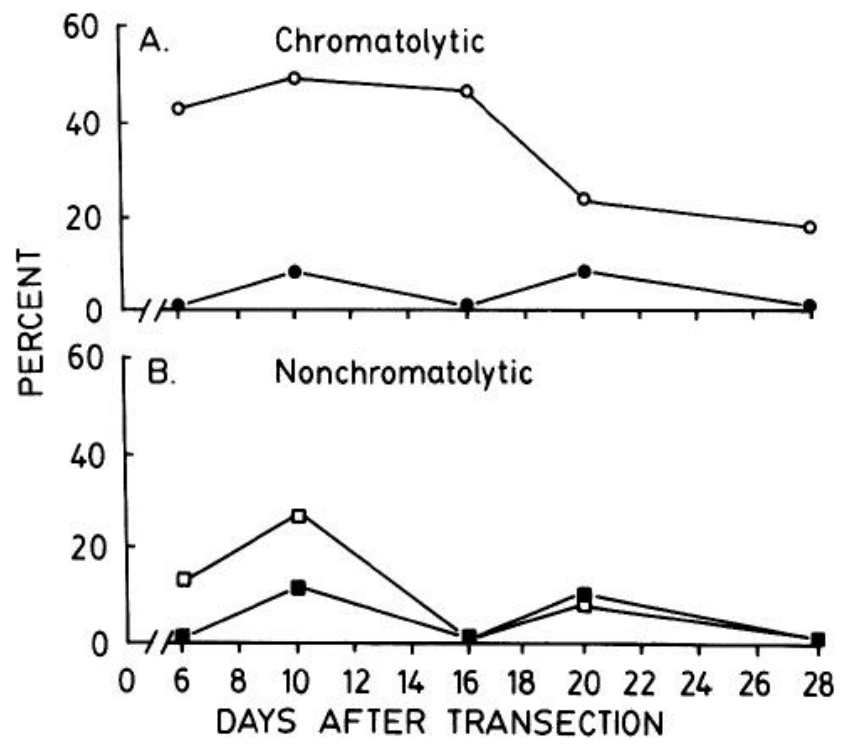

Figure 5. Percentage of large DRG cells unstained in paraffin sections by the dephosphorylation-dependent antibody RMDO 20.11 at a dilution of $1: 100,000$ as a function of the number of days following transection of the right sciatic nerve. Circles, chromatolytic cells; squares, nonchromatolytic cells; open symbols, cells of the right (experimental) DRG; closed symbols, cells of the left (control) DRG. The percentage of cells unstained in the large, chromatolytic cell population of the experimental DRG increases over the control following transection $(A)$, indicating a decrease in dephosphorylation, while the percentage of cells unstained in the large, nonchromatolytic cell population of the experimental DRG remains at control levels following transection $(B)$. A decrease in dephosphorylation may therefore be correlated with an increase in chromatolysis. compared to that in axons, depended upon the specificity and titer of the antibody. Antibody RMDO 20.11 to NF200-dP stained perikarya selectively at very high dilutions $(1: 150,000)$ but also stained axons when applied at lower dilutions (1:5000). Likewise, antibodies to NF200-P and NF150-P (e.g., RMO 24.9 and RMO 45, respectively) stained axons selectively at high dilutions (1:100), but also stained perikarya of some large neurons undiluted.

In general, the ratio of perikaryal to axonal staining for each NF200- and NF150-specific antibody corresponded to the ability of the antibody to recognize dephosphorylated versus phosphorylated forms of NF200 and NF150 when immunoblotted with NF preparations that had been progressively dephosphorylated with alkaline phosphatase (see Carden et al., 1985). Furthermore, it was noted that antibodies to NF200-P and NF150-P stained large neuronal perikarya in DRG much more readily (i.e., at higher dilutions) than they did perikarya of neurons within the CNS (e.g., anterior horn cells) when applied at the same dilution.

\section{Immunocytochemistry of DRG following nerve transection}

Immunoreactivity to phosphorylation-dependent epitopes (NF200-P and NF150-P) increased in the neuronal perikarya of the right (experimental) L4 and L5 DRG following nerve transection (Fig. 2A), as compared with the left (control) L4 and L5 DRG (Fig. $2 B$ ) from the same animal. The enhanced staining was usually diffuse within the cell body, but occasionally occurred preferentially around the nucleus. Increased immunoreactivity varied among different populations of neurons, occurring most prominently in large neurons and especially in cells that revealed a chromatolytic reaction (Fig. 3). Immunostaining by antibody RMO 24.9 (to NF200-P) among large chromatolytic neurons increased from $15.4 \%$ at day 6 after transection to $56.5 \%$ at day 20 , declining to $29.5 \%$ at day 28 after transection. Similar increases of immunoreactivity were noted with 2 

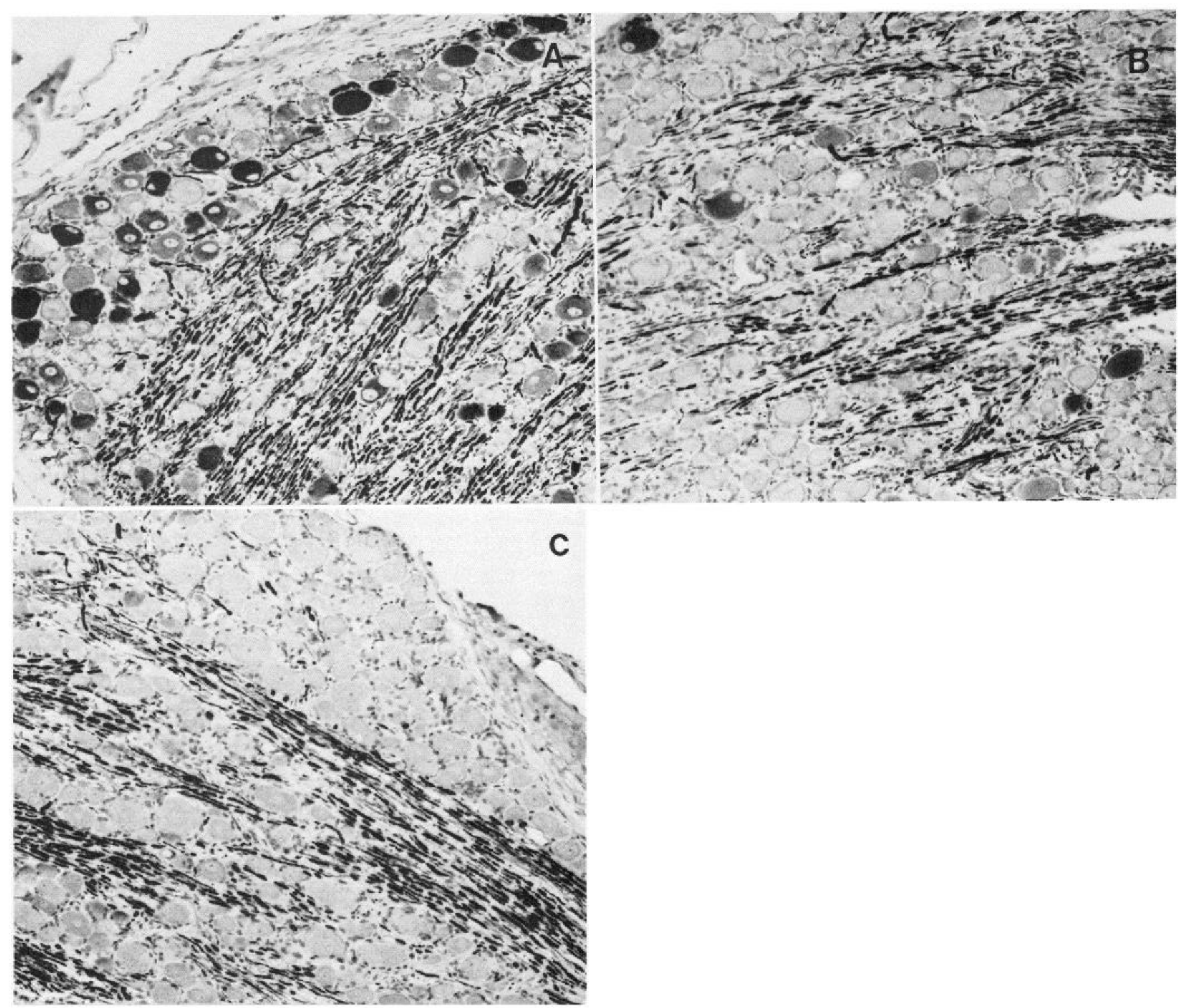

Figure 6. Photomicrographs of $6 \mu \mathrm{m}$ paraffin sections of $(A)$ left L4-L5 DRG $6 \mathrm{~d}$ following proximal transection, of $(B)$ right L4-L5 DRG $6 \mathrm{~d}$ following distal transection of the sciatic nerve, and of $(C)$ control root ganglia $6 \mathrm{~d}$ following proximal transection. All ganglia are from the same animal. Sections were stained immunocytochemically with the phosphorylation-dependent monoclonal antibody RMO 217 to NF200 at a dilution of 1:10. In the control ganglia, chromatolysis and immunoreactivity are absent. The levels of chromatolysis and immunoreactivity following proximal transection are increased beyond the enhancement that occurs following distal transection. Large, chromatolytic neurons are preferentially stained.

other antibody probes to NF200-P (RMO 217 and Ta51) and with all 3 antibodies to NF150-P (RMO 108.1, RMO 45, and RMO 55). No increase of perikaryal staining was observed among the chromatolytic cells of the control DRG (Fig. $3 A$ ) or the nonchromatolytic cells of the control and experimental DRG (Fig. 3B). Staining increased slightly among the small cell populations of the experimental DRG.

A decrease in immunoreactivity to dephosphorylation-dependent epitopes (NF200-dP) by antibody RMDO 20.11 occurred in the neuronal perikarya of the right (experimental) L4 and L5 DRG following nerve transection (Fig. $4 A$ ), as compared with those in the left (control) L4 and L5 DRG (Fig. 4B). The decreased immunoreactivity occurred predominantly, though not exclusively, in the large chromatolytic cell bodies of the experimental DRG. In the large cell population, fewer cell bodies were stained in the experimental DRG, and the percentage of cell bodies unstained increased (Fig. 5). At day 6 following transection, the percentage of unstained large cells increased to $43.5 \%$, then declined to $23.5 \%$ at day 16 and to $17.1 \%$ at day 28. No decrease in immunoreactivity to dephosphorylationdependent epitopes was observed in the control chromatolytic cells (Fig. $5 A$ ) or in the nonchromatolytic cell population (Fig. $5 B$ ). In the small cell population, a small decrease was observed between levels of staining in the control and experimental DRG. No difference was observed between control and experimental DRG stained with phosphorylation-independent antibodies to NF200 (RMO 194), NF150 (RMDO 10), and NF68 (RMS 21).

\section{Immunocytochemistry of $D R G$, distal versus proximal nerve transection}

Fragmentation and reduction of Nissl substance could be detected to a small but variable extent among neurons of the L4- 


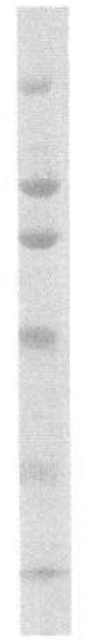

3

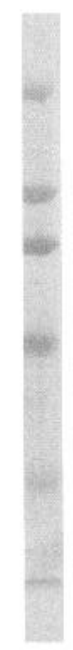

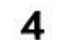

Figure 7. Immunoblots of experimental (lanes 1 and 3) and control (lanes 2 and 4) DRG homogenates $21 \mathrm{~d}$ after transection of the right sciatic nerve, stained immunocytochemically with hybridoma supernatants of the phosphorylation-dependent antibody RMO 24.9 (lanes 1 and 2) and the dephosphorylation-dependent antibody RMDO 20.11 (lanes 3 and 4). Antibody RMO 24.9 stains NF200-P in the experimental DRG more intensely than the control, indicating an increase in phosphorylation, and antibody RMDO 20.11 stains NF200-dP in the experimental DRG less intensely than the control, indicating a decrease in dephosphorylation following transection. There is no qualitative difference between the experimental and control staining patterns. Molecular-weight standards are myosin, 200,000, $\beta$-galactosidase, 116,500, phosphorylase B, 92,500 , bovine serum albumin, 66,000 , and ovalbumin, 45,000 .

L5 DRG at $3 \mathrm{~d}$ following distal nerve transections. These earliest changes of chromatolysis were not accompanied by increases of immunoreactivity to either RMO 24.9 , RMO 217 , or Ta51 (NF200-P) or to RMO 108.1, RMO 45, or RMO 55 (NF150P), nor by decreased reactivity to RMDO 20.11 (NF200-dP). More extensive chromatolysis, i.e., peripheral margination of Nissl substance, occurred in the contralateral DRG as a result of a proximal nerve transection. Some increased immunoreactivity to NF200-P and NF150-P was seen among the scattered chromatolytic large cells.

A more dramatic difference in the extent of chromatolysis and in the immunoreactivities to NF-P and NF-dP following proximal versus distal nerve transections was noted at day 6 (Fig. 6). Proximal nerve transection led to extensive chromatolysis and increased immunoreactivity to NF200-P (Fig. 6A) compared to the changes following distal nerve transection in the contralateral DRG (Fig. $6 B$ ) and the control DRG in the same animal (Fig. 6C). Immunoreactivity to NF150-P was similarly increased, while reactivity to NF200-dP was diminished. Similar changes in chromatolytic response and immunoreactivities were noted in DRG of proximally transected nerve at 10 , 14 , and $18 \mathrm{~d}$.

\section{Immunocytochemistry of the spinal cord following nerve transection}

Chromatolysis and alterations of immunoreactivity in NF-P and NF-dP were much less apparent in motor neurons than in sensory neurons of the same transected nerves. Quantitation of these changes in motor neurons was complicated by the inability to identify with certainty the perikarya of transected nerves other

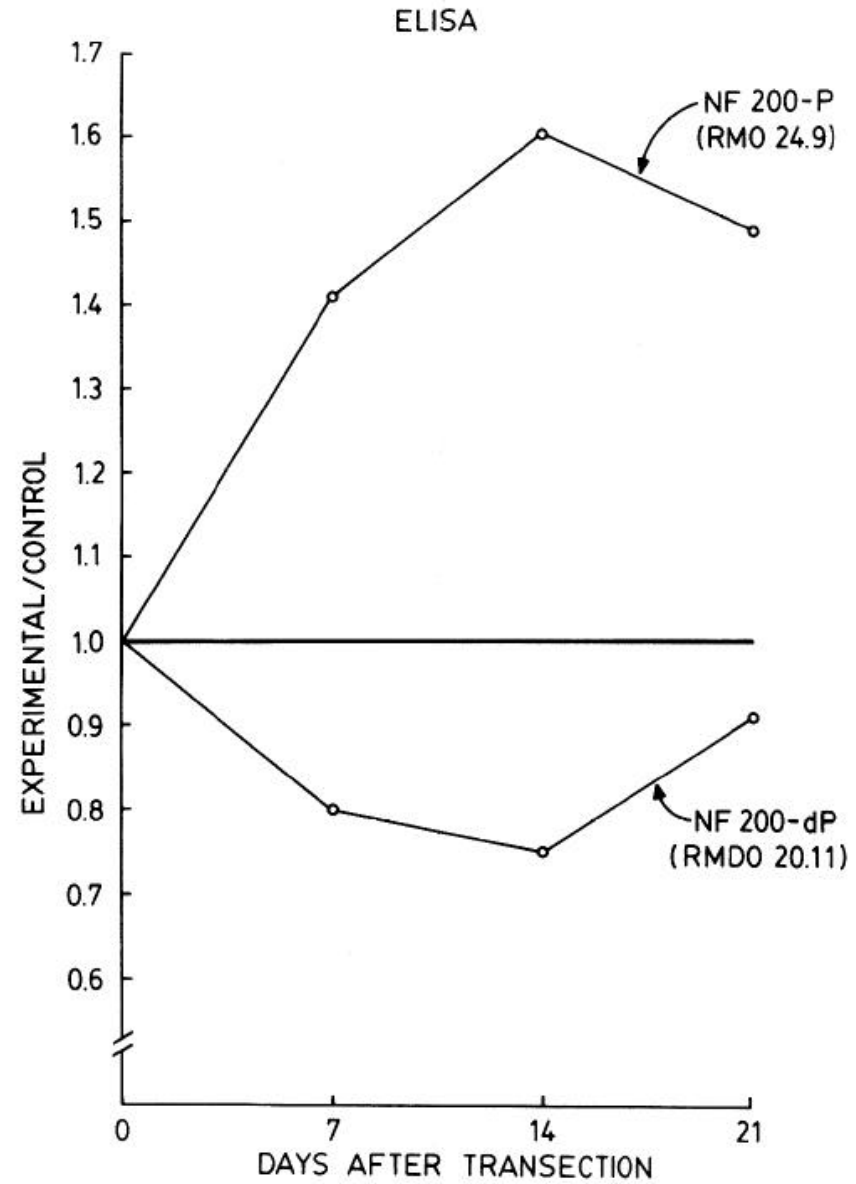

Figure 8. ELISA results expressed as a ratio of the experimental (normalized) to the control values obtained with hybridoma supernatants of the phosphorylation-dependent antibody RMO 24.9 and the dephosphorylation-dependent antibody RMDO 20.11. At 7, 14, and 21 d following transection, the ratio of experimental to control is significantly greater than 1.0 , using antibody RMO 24.9, indicating an increase in phosphorylation. At $7 \mathrm{~d}$ following transection, the ratio of experimental to control, using antibody RMDO 20.11 , is significantly less than 1.0, indicating a decrease in dephosphorylation. The ratios at 14 and $21 \mathrm{~d}$ are not significantly less than 1.0.

than those that manifested some alterations, unlike perikarya of large motor neurons in the same section but from the contralateral side of spinal cord. Parent motor neurons of transected neurites were most readily identified by loss of dendrites (Sumner and Watson, 1971), as visualized by immunostain to antibody 20.11 (NF200-dP). Altered perikarya were located in the ventrolateral and dorsolateral portions of the ventral horn following proximal transection, but were predominantly in the dorsolateral portion of the same lumbar cord following distal transection. Afflicted perikarya showed a mildly, but variably, decreased immunoreactivity to RMDO 20.11 (NF200-dP); some also revealed an increased immunoreactivity to RMO 24.9, RMO 217, and Ta51 (NF200-P) and to RMO 45 and RMO 55 (NF150$\mathrm{P})$. These changes of immunoreactivity were more evident after proximal than after distal transections.

\section{Immunoblot}

Immunoblots of homogenates of DRG were stained by each of the monoclonal antibodies described above. No qualitative changes in banding patterns were observed after transection. At 
3 weeks following transection (Fig. 7), the phosphorylation-dependent antibody RMO 24.9 stained the experimental DRG more intensely than it did the control, and the dephosphorylation-dependent antibody RMDO 20.11 stained the experimental DRG less intensely than it did the control.

\section{ELISA assay}

The ELISA assay was used to quantitate immunoreactivities to NF200-P and NF200-dP in experimental and control DRG in order to determine whether changes of immunoreactivities reflected an overall increase of NF or were selective for phosphorylatcd or dcphosphorylated forms of NF. Values were normalized against the reactivity of the antibody RMDO 10, which reacts strongly with a core epitope on NF150. Use of an "internal" NF baseline standard obviated the difficulties due to changes in protein and nucleic acid contents of experimental DRG when using the usual "external" standards.

The ratio of experimental to control values obtained using the phosphorylation-dependent antibody RMO 24.9 was significantly greater than 1.0 at days $7(p<0.05), 14(p<0.025)$, and $21(p<0.05)$ (Fig. 8). The ratio of experimental to control values obtained using the dephosphorylation-dependent antibody RMDO 20.11 was significantly less than 1.0 at day 7 ( $p<$ 0.10 ). The ratios at days 14 and 21 posttransection were not significantly less than 1.0 (Fig. 8).

\section{Discussion}

An increase of phosphorylated forms and a decrease of dephosphorylated forms of neurofilament proteins, compared to phosphate-independent forms, have now been demonstrated in the perikarya of axotomized neurons. These findings confirm and extend the observations by Moss and Lewkowicz (1983) and Drager and Hofbauer (1984) of increased immunostaining to NF-P in the perikarya of transected nerves. Use of multiple antibodies to NF-P, NF-dP, and NF-ind epitopes on neurofilament proteins enabled the nature of immunological change to be defined, especially with regard to the question of whether increases of immunoreactivity to NF-P represent specific or generalized alterations of neurofilament proteins. It has now been established by histochemical and biochemical methods that there is an enhanced state of neurofilament phosphorylation in axotomized neurons of rat DRG independent of whether there is also an increase in the numbers of neurofilaments (Pannese, 1963; Lieberman, 1971; Torvik and Skjorten, 1971; Zelena, 1971; Horoupian and Wisneiwski, 1972; Price and Porter, 1972; Wisotzkey and Cole, 1974; Torvik, 1976) or an increase in the amount of neurofilament proteins (Sinicropi and McIlwain, 1983) in the perikarya of transected nerve.

Increased phosphorylation was detected by a wide range of antibodies that recognized different epitopes on NF200 and NF150. These findings suggest the addition of multiple phosphate residues onto both NF200 and NF150, although the immunological responses to phosphorylation could also be augmented by conformational changes rather than by direct modifications of antigenic sites (Carden et al., 1985). Immunological effects may also be mediated preferentially by phosphorylation at specific sites or on selected residues. Similarly, phosphorylation may have differential effects on antibodies that react with dephosphorylated sites or states, thereby accounting for the dissimilarities in the time courses by which changes in NF-P and NF-dP become manifest within the same neuronal perikarya of transected nerve.
Changes in neurofilament immunoreactivities indicative of increased phosphorylation correlate closely with chromatolytic changes in DRG neurons, especially in neurons of large size, which preferentially express neurofilament proteins (Anderton et al., 1982; Sharp et al., 1982; Lawson et al., 1984; Price, 1985). The absence of neurofilament expression, or low levels thereof, would preclude the immunological detection of DRG neurons, as occurs with chromatolytic neurons of small size. As noted with chromatolysis (Humbertson, 1963; Watson, 1968; Torvik, 1976; Aldskogius and Arvidsson, 1978), more proximal sectioning of sciatic nerve causes an enhancement of neurofilament phosphorylation in perikarya, as wcll as a foreshortening of the interval prior to the appearance of change. Lack of change among nonchromatolytic neurons in experimental DRG provides further evidence that increased phosphorylation is part of the chromatolytic response. Of course, some nonchromatolytic neurons may represent a group whose axons bypass the site of nerve transection.

Localization of immunoreactivity to NF-dP in perikarya and to NF-P in neurites (Sternberger and Sternberger, 1983) indicates that neurofilaments are generally phosphorylated immediately prior to or during the prolonged transit of neurofilaments through the axon. Small but variable amounts of immunoreactivity to NF-P can also be detected in neuronal perikarya, especially in DRG neurons, which suggests that perikaryal neurofilaments are also present in varying states of phosphorylation. Indeed, the relatively high "resting" levels of neurofilament phosphorylation in DRG neurons may be a major factor in facilitating the detection of increased states of phosphorylation during chromatolysis of the primary sensory neurons. Similar increases of NF-P were not seen in motor neurons of the same transected nerves, which was possibly due to (1) a lower "resting"level of neurofilament phosphorylation in the anterior horn cells, or (2) the increased distance between the site of nerve transection and the neuronal perikarya, resulting in a weaker signal both for chromatolysis and phosphorylation of neurofilaments. Moss and Lewkowicz (1983) detected only a minor change of immunoreactivity to NF-P in motor neurons when increased immunostaining to NF-P in retinal ganglion cells was induced by nerve transections in close proximity to the neuronal perikarya (Drager and Hofbauer, 1984).

While phosphorylation markedly alters the immunological (Sternberger and Sternberger, 1983) and physical properties of NF200 and NF150 (Julien and Mushinsky, 1983), especially their COOH-terminal domains (Carden et al., 1985), the effects of phosphorylation on neurofilament metabolism are still unknown. Recent ${ }^{31} \mathrm{P}-\mathrm{NMR}$ studies show the clustering of phosphoserine residues on the external aspects of NF200 and NF150 (Zimmerman and Schlaepfer, 1986). These phosphorylation sites are ideally positioned to alter the interactions between neurofilaments and the surrounding microenvironment, thcrcby effecting the movement of neurofilaments through the perikaryon and/or axon. Increased phosphorylation could slow or block neurofilament movement, especially through the perikaryon, thus accounting for the diminished transport of neurofilaments into and along the axons of transected nerve (Hoffman and Lasek, 1980). Increased phosphorylation of neurofilaments could also reflect enhanced kinase activity or, alternatively, an epiphenomenal event of filaments whose residence in the perikaryon had been prolonged.

Some evidence that phosphorylation may block the perikaryal transport of neurofilaments is seen during experimental alu- 
minum intoxication. Massive accumulations of neurofilaments in the perikarya, dendrites, and proximal axons of motor neurons (Klatzo et al., 1965; Wisniewski et al., 1980; Troncoso et al., 1982; Ghetti and Gambetti, 1983), caused by a block in transport (Bizzi et al., 1984; Troncoso et al., 1985), are associated with a marked increase of immunoreactivity to NF-P over that to NF-dP (Troncoso et al., 1985). It is noteworthy that the stigmata of chromatolysis are not apparent in neurons afflicted by aluminum toxicity; nor is there any evidence that these neurons are subject to diminished neurofilament protein synthesis, as is noted in axotomized neurons (P. N. Hoffman, personal communication). Indeed, the pathology of aluminum intoxication appears to reflect the continued synthesis and assembly of neurofilaments in spite of a blockage in their passage into the axon.

Finally, a relationship between neurofilament phosphorylation and the neurofibrillary pathology of Alzheimer's disease has also been proposed (N. H. Sternberger et al., 1985; Ulrich et al., 1985; Cork et al., 1986). The increased immunoreactivity of neurofibrillary tangles to NF-P could reflect abnormal phosphorylation of neurofilament proteins before or after their association with paired helical filaments (PHF). The observed immunoreactivities could also be due to preferential incorporation of phesphorylated epitopes into PHF, their modification during incorporation, or cross-reactivities with phosphorylated epitopes on other cytoskeletal proteins of PHF (Kosik et al., 1986). It is also possible that increased phosphorylation may be a reactive response of altered neurons. Further insights into pathogenetic mechanisms of complex disease states will require a more advanced state of understanding of the metabolic pathways of neurofilaments and of their interactions with other components, enzymes, and factors of the neuronal cytoskeleton.

\section{References}

Aldskogius, H., and J. Arvidsson (1978) Nerve cell degeneration and death in the trigeminal ganglion of adult rat following peripheral nerve transection. J. Neurocytol. 7: 229-250.

Anderton, B., H. B. Coakham, J. A. Garson, A. A. Harper, E. I. Harper, and S. N. Lawson (1982) A monoclonal antibody against neurofilament protein specifically labels the large light cell population in rat dorsal root ganglia. J. Physiol. (Lond.) 334: 97-98P.

Bizzi, A., R. C. Crane, L. Autilio-Gambetti, and P. Gambetti (1984) Aluminum effect on slow axonal transport: A novel impairment of neurofilament transport. J. Neurosci. 4: 722-731.

Burrell, H. R., A. M. Heacock, R. D. Water, and B. W. Agranoff (1979) Increased tubulin messenger RNA in the goldfish retina during optic nerve regeneration. Brain Res. 168: 628-632.

Carden, M. J., W. W. Schlaepfer, and V. M.-Y. Lee (1985) The structurc, biochemical propertics, and immunogenicity of neurofilament peripheral regions are determined by phosphorylation state. J. Biol. Chem. 260: 9805-9817.

Carmel, P. W., and B. M. Stein (1969) Cell changes in sensory ganglia following proximal and distal nerve section in the monkey. J. Comp. Neurol. 135: 145-166.

Cavanaugh, M. W. (1951) Quantitative effects of the peripheral innervation area on nerves and spinal ganglion cells. J. Comp. Neurol. 94: $181-219$

Cork, L. C., N. H. Sternberger, L. A. Sternberger, M. F. Casanova, R. G. Struble, and D. L. Price (1986) Phosphorylated neurofilament antigens in neurofibrillary tangles in Alzheimer's disease. J. Neuropathol. Exp. Neurol. 45: 56-64.

Cragg, B. G. (1970) What is the signal for chromatolysis? Brain Res. 23: $1-21$.

Drager, U. C., and A. Hofbauer (1984) Antibodies to heavy neurofilament subunit detect a subpopulation of damaged ganglion cells in retina. Nature 309: 624-626.

Fine, R. E., and D. Bray (1971) Actin in growing nerve cells. Nature 234: 115-118.
Ghetti, B., and P. Gambetti (1983) Comparative immunocytochemical characterization of neurofibrillary tangles in experimental maytansine and aluminum encephalopathies. Brain Res. 276: 388-393.

Giulian, D., H. Des Ruisseaux, and D. Cowburn (1980) Biosynthesis and intra-axonal transport of proteins during neuronal regeneration. J. Biol. Chem. 255: 6494-6501.

Grafstein, B. (1975) The nerve cell body response to axotomy. Exp. Neurol. 48: 32-51.

Guth, L. (1956) Regeneration in the mammalian peripheral nervous system. Physiol. Rev. 36: 441-478.

Hall, M. E., D. L. Wilson, and G. C. Stone (1978) Changes in synthesis of specific proteins following axotomy: Detection with two-dimensional gel electrophoresis. J. Neurobiol. 9: 353-366.

Heacock, A. M., and B. W. Agranoff (1976) Enhanced labeling of a retinal protein during regencration of optic nerve in goldfish. Proc. Natl. Acad. Sci. USA 73; 828-832.

Hoffman, P. N., and R. J. Lasek (1980) Axonal transport of the cytoskeleton in regenerating motor neurons: Constancy and change. Brain Res. 202: 317-333.

Horoupian, D., and H. Wisneiwski (1972) Neurofilamentary hyperplasia in inferior olivary hypertrophy. J. Neuropathol. Exp. Neurol. 31: 186 .

Hughs, J. T. (1978) Central chromatolysis. In Pathology of the Spinal Cord, pp. 3-5, Lloyd-Luke, London.

Humbertson, A. (1963) A chronological study of degenerative phenomena of dorsal root ganglion cells following section of the sciatic nerve. Anat. Rec. 145: 244.

Julien, J.-P., and W. E. Mushinsky (1983) The distribution of phosphorylation sitcs among identificd proteolytic fragments of mammalian neurofilaments. J. Biol. Chem. 258: 4019-4095.

Kennett, R. H. (1980) Enzyme-linked antibody assay with cells attached to polyvinyl chloride plates. In Monoclonal Antibodies, R. H. Kennett, T. J. McKearn, and K. B. Bechtol, eds., pp. 376-377, Plenum, New York.

Kirkpatrick, J. B. (1968) Chromatolysis in the hypoglossal nucleus of the rat: An electron microscopic analysis. J. Comp. Neurol. 132: 189212.

Klatzo, I., H. Wisniewski, and E. Streicher (1965) Experimental production of neurofibrillary degeneration. I. Light microscopic observations. J. Neuropathol. Exp. Neurol. 24: 187-199.

Kosik, K. S., C. L. Joachim, and D. J. Selkoe (1986) Microtubuleassociated protein tau $(\tau)$ is a major antigenic component of paired helical filaments in Alzhcimer discase. Proc. Natl. Acad. Sci. USA 83: 4044-4048.

Laemmli, U.-K. (1970) Cleavage of structural proteins during the assembly of the head of bacteriophage T4. Nature 227: 680-685.

Lasek, R. J., and P. N. Hoffman (1976) The neuronal cytoskeleton, axonal transport and axonal growth. In Cell Motility, Vol. 3, R. Goldman, T. Pollard, and J. Rosenbaum, eds., pp. 1021-1049, Cold Spring Harbor Laboratory, Cold Spring Harbor, NY.

Lawson, S. N. (1979) The postnatal development of large light and small dark neurons in mouse dorsal root ganglia: A statistical analysis of cell numbers and size. J. Neurocytol. 8: 275-294.

Lawson, S. N., K. W. T. Caddy, and T. J. Biscoe (1974) Development of dorsal root ganglion neurones. Studies of cell birthdays and changes in mean cell diameters. Cell Tissue Res. 153: 399-413.

Lawson, S. N., A. A. Harper, E. I. Harper, J. $\Lambda$. Garson, and B. H. Anderton (1984) A monoclonal antibody against neurofilament protein specifically labels a subpopulation of rat sensory neurons. J. Comp. Neurol. 228: 263-272.

Lee, V. M.-Y., H.-L. Wu, and W. W. Schlaepfer (1982) Monoclonal antibodies recognize individual neurofilament triplet proteins. Proc. Natl. Acad. Sci. USA 79: 6089-6092.

Lee, V. M.-Y., C. D. Page, H.-L. Wu, and W. W. Schlaepfer (1984) Monoclonal antibodies to gel excised glial filament protein and their reactivity with other intermediate filament proteins. J. Neurochem. $42: 25-32$.

Lieberman, A. R. (1971) The axon reaction: A review of the principal features of perikaryal responses to axon injury. Int. Rev. Neurobiol. 14: 49-124.

Marchisio, P. C., M. Osborn, and K. Weber (1978) Changes in intracellular organization of tubulin and actin in N-18 neuroblastoma cells during the process of axon extension induced by serum deprivation. Brain Res. 155: 229-238.

McKnight, G. S. (1977) A colorimetric method for the determination of submicrogram quantities of protein. Anal. Biochem. 31: 146-148. 
Moss, T. H., and S. J. Lewkowicz (1983) The axon reaction in motor and sensory neurones of mice studied by a monoclonal antibody marker of neurofilament protein. J. Neurol. Sci. 60: 267-280.

Pannese, E. (1963) Investigations on the ultrastructural changes of the spinal ganglion neurones in the course of axon regeneration and cell hypertrophy. Z. Zellforsch. Mikrosk. Anat. 61: 561-586.

Peters, A., and J. E. Vaughn (1967) Microtubules and filaments in the axons and astrocytes of early postnatal optic nerves. J. Cell Biol. 32: 113-119.

Price, D. L., and K. R. Porter (1972) The response of ventral horn neurons to axonal transection. J. Cell Biol. 53: 24-37.

Price, J. (1985) An immunocytochemical and quantitative examination of dorsal root ganglion neuronal subpopulations. J. Neurosci. 5: 2051-2059.

Sharp, G. A., G. Shaw, and K. Weber (1982) Immunoelectron-microscopical localization of the three neurofilament triplet proteins along neurofilaments of cultured dorsal root ganglion neurons. Exp. Cell Res. 137: 403-413.

Shaw, G., M. Osborn, and K. Weber (1981) Arrangement of neurofilaments, microtubules and microfilament-associated proteins in cultured dorsal root ganglia cells. Eur. J. Cell Biol. 24: 20-27.

Sinicropi, D. V., and D. L. McIlwain (1983) Changes in the amounts of cytoskeletal proteins within the perikarya and axons of regenerating frog motoneurons. J. Cell Biol. 96: 240-247.

Skene, J. H. P., and M. Willard (1981) Changes in axonally transported proteins during axon regeneration in toad retinal ganglion cells. $\mathbf{J}$. Cell Biol. 89: 86-95.

Sommer, E. W., J. Kazimierczak, and B. Droz (1985) Neuronal subpopulations in the dorsal root ganglion of the mouse as characterized by combination of ultrastructural and cytochemical features. Brain Res. 346: 310-326.

Sterman, A. B., and M. R. Delannoy (1985) Cell body responses to axonal injury: Traumatic axotomy versus toxic neuropathy. Exp. Neurol. 89: 408-419.

Sternberger, L. A. (1986) Immunocytochemistry, 3rd Ed., Wiley, New York.

Sternberger, L. A., and N. H. Sternberger (1983) Monoclonal antibodies distinguish phosphorylated and non-phosphorylated forms of neurofilaments in situ. Proc. Natl. Acad. Sci. USA 80: 6126-6130.

Sternberger, L. A., P. H. Hardy, Jr., J. J. Cuculis, and H. G. Meyer (1970) The unlabeled antibody enzyme method of immunohistochemistry. Preparation and properties of soluble antigen-antibody complex (horseradish peroxidase-antihorseradish peroxidase) and its use in identification of spirochetes. J. Histochem. Cytochem. 18:315333.

Sternberger, N. H., L. A. Sternberger, and J. Ulrich (1985) Aberrant neurofilament phosphorylation in Alzheimer's disease. Proc. Natl. Acad. Sci. USA 82: 4274-4276.
Sumner, B. E. H., and W. E. Watson (1971) Retraction and expansion of the dendritic tree of motor neurones of adult rats induced in vivo. Nature 233: 273-275.

Tennvson, V. M., and M. D. Gershon (1984) Light and electron microscopy of dorsal root, sympathetic and enteric ganglia. In Peripheral Neuropathy, Vol. I, P. J. Dyck, P. K. Thomas, E. H. Lambert, and R. Bunge, eds., pp. 121-155, Saunders, Philadelphia, PA.

Torvik, A. (1976) Central chromatolysis and the axon reaction: A reappraisal. Neuropathol. Appl. Neurobiol. 2: 423-432.

Torvik, A., and F. Skjorten (1971) Electron microscopic observations on nerve cell regeneration and degeneration after axon lesions. Acta Neuropathol. (Berl.) 17: 248-264.

Towbin, H., T. Staeblin, and J. Gordon (1979) Electrophoretic transfer of proteins from polyacrylamide gels to nitrocellulose sheets: Procedure and some applications. Proc. Natl. Acad. Sci. USA 76: 43504354.

Trojanowski, J. Q., M. A. Obrocka, and V. M.-Y. Lee (1985) Distribution of neurofilament subunits in neurons and neuronal processes: Immunohistochemical studies of bovine cerebellum with subunitspecific monoclonal antibodies. J. Histochem. Cytochem. 33: 557563.

Troncoso, J. C., D. L. Price, J. W. Griffin, and I. M. Parhad (1982) Neurofibrillary axonal pathology in aluminum intoxication. Ann. Neurol. 12: 278-283.

Troncoso, J. C., P. N. Hoffman, J. W. Griffin, K. M. Hess-Kozlow, and D. L. Price (1985) Aluminum intoxication: A disorder of neurofilament transport in motor neurons. Brain Res. 342: 172-175.

Ulrich, J., M. Haugh, B. H. Anderton, and A. Probst (1985) Phosphorylated epitopes on Pick bodies (PB) and Alzheimer neurofibrillary tangles (NFT). J. Neuropathol. Exp. Neurol. 44: 367.

Watson, W. E. (1968) Observations on the nucleolar and total cell body nucleic acid of injured nerve cells. J. Physiol. (Lond.) 196:655676.

Wisniewski, H. M., J. A. Sturman, and J. W. Shek (1980) Aluminum chloride induced neurofibrillary changes in the developing rabbit: A chronic animal model. Ann. Neurol. 8: 479-490.

Wisotzkey, H., and M. Cole (1974) Reversible neurofilamentous change with deafferentation of the inferior olive in the monkey. J. Neuropathol. Exp. Neurol. 33: 187.

Yamada, K. M., B. S. Spooner, and N. K. Wessells (1971) Ultrastructure and function of growth cones and axons of cultured nerve cells. J. Cell Biol. 49: 614-635.

Zelena, J. (1971) Neurofilaments and microtubules in sensory neurons after peripheral nerve section. Z. Zellforsch. Mikrosk. Anat. 117: 191211.

Zimmerman, U.-J. P., and W. W. Schlaepfer (1986) Clustering of phosphorylated amino acid residues in neurofilament proteins as revealed by ${ }^{31} \mathrm{P}$ NMR. Biochemistry $25: 3533-3536$. 